\title{
Myeloid Cells Enriched for a Dendritic Cell Population From People Living With HIV Have Altered Gene Expression Not Restored by Antiretroviral Therapy
}

OPEN ACCESS

Edited by:

Mario Clerici,

University of Milan, Italy

Reviewed by:

Cristian Apetrei,

University of Pittsburgh, United States

Nicholas Funderburg,

The Ohio State University,

United States

*Correspondence:

Shannon M. Murray

smurray@fredhutch.org

${ }^{\dagger}$ Present address:

Shannon M. Murray,

Fred Hutchinson Cancer

Research Center, Division of Basic Sciences, Seattle, WA, United States

Yuwei Zhang

University of Texas, MD Anderson

Cancer Center, Houston, TX,

United States

Rafick P. Sekaly,

Department of Pathology, Case

Western Reserve University

Cleveland, $\mathrm{OH}$, United States

Specialty section

This article was submitted to

Viral Immunology,

a section of the journal

Frontiers in Immunology

Received: 09 November 2019

Accepted: 31 January 2020

Published: 04 March 2020

Citation:

Murray SM, Zhang Y, Douek DC and

Sekaly RP (2020) Myeloid Cells

Enriched for a Dendritic Cell Population From People Living With HIV Have Altered Gene Expression

Not Restored by Antiretroviral

Therapy. Front. Immunol. 11:261.

doi: 10.3389/fimmu.2020.00261

\author{
Shannon M. Murray ${ }^{1 \star \dagger}$, Yuwei Zhang ${ }^{2 \dagger}$, Daniel C. Douek ${ }^{1}$ and Rafick P. Sekaly ${ }^{2 \dagger}$ \\ ${ }^{1}$ Human Immunology Section, Vaccine Research Center, National Institute of Allergy and Infectious Diseases, National \\ Institutes of Health, Bethesda, MD, United States, ${ }^{2}$ Vaccine and Gene Therapy Institute Florida, Port St. Lucie, FL, \\ United States
}

Antiretroviral therapy (ART) for human immunodeficiency virus (HIV) infections has been designed to optimize CD4 T-cell survival and limit HIV replication. Cell types other than CD4T cells such as monocytes/macrophage, dendritic cells, and granulocytes (collectively known as myeloid cells), are generally not considered in the development of ART protocols. Myeloid dendritic cells (mDCs) are the most potent inducers of CD4 T-cell activation and central to the regulation of immune responses. mDCs in the blood are decreased in number, altered in function, and implicated in promoting HIV latency in people living with HIV (PLWH). We found that cells enriched for mDC in PLWH had transcriptional changes compared to $\mathrm{mDC}$ from HIV uninfected individuals, some of which were not completely restored by ART. In contrast, other mDC functions such as interleukin-1 signaling and type I interferon pathways were restored by ART. Some of the transcriptional changes in $\mathrm{mDC}$ not completely reversed by ART were enriched in genes that are classically associated with cells of the monocyte/macrophage lineage, but new single-cell RNA sequencing studies show that they are also expressed by a subset of mDC. A cellular enzyme, acyloxyacyl hydrolase (AOAH), important for lipopolysaccharide (LPS) detoxification, had increased transcription in $\mathrm{mDC}$ of PLWH, not restored by ART. It is possible that one reason ART is not completely successful in PLWH is the failure to phenotypically change the mDCs. Thus, inability of ART to be completely effective might involve myeloid cells and the failure to restore $\mathrm{mDC}$ function as measured by gene transcription. We suggest that $\mathrm{mDC}$ and myeloid cells should be considered in future combination ART development.

Keywords: human immunodeficiency virus (HIV), antiretroviral therapy (ART), pathogenesis, dendritic cells, myeloid cells, monocytes

\section{INTRODUCTION}

Dendritic cells (DCs) and monocytes are innate immune cells of the myeloid lineage that play critical roles in protection against microbial infections $(1,2)$. DCs internalize microbes in endocytic compartments where microbes are degraded into components. The resulting antigens are presented to $\mathrm{T}$ and $\mathrm{B}$ cells to stimulate immune responses against that microbe. In contrast, monocytes, which 
differentiate into macrophage within tissues, are specialized to degrade and scavenge microbes from the host organism (1). Monocytes/macrophage can also present antigens; however, it is important to note that DCs are $>100$-fold more potent in activating $T$ cells through their antigen-presenting functions than are monocytes/macrophage (1).

DC and monocytes are generated in the bone marrow during hematopoiesis. These two cell types share a common hematopoietic progenitor, the monocyte and DC precursor (MDP) (3-5). Two branches of differentiation are thought to arise from the MDP: one branch to monocytes and another branch to a common DC progenitor (CDP) $(6,7)$. As we are focusing on $\mathrm{DC}$, it is important to know that the CDP generates at least three DC subpopulations. The three major DC populations are the myeloid DC type 1 ( $\mathrm{mDC} 1), 2(\mathrm{mDC} 2)$, and plasmacytoid DC (pDC) $(5,8)$. mDC2 is the most frequent and is known as conventional DC $(6,7,9)$. Recent single-cell RNA sequencing (scRNAseq) of $\mathrm{mDC}$ from healthy humans revealed that the $\mathrm{mDC} 2$ population is comprised of two transcriptionally distinct subsets, one newly defined, which expressed certain genes traditionally associated with monocyte/macrophage (10). Herein, we concentrate our studies on $\mathrm{mDC} 2$, also known as conventional DC type $2(\mathrm{cDC} 2)$ or $\mathrm{CD}_{1} \mathrm{c}^{+} \mathrm{mDC}$, the largest DC subset. This subset will be called $\mathrm{mDC}$ in our studies. We will focus on this subset in the peripheral blood before cells migrate to different tissue types and are designated by some as "precursor-DC" (pre-DC) [reviewed in Collin and Bigley (9)].

A major effect of HIV-1 (herein called HIV) infections is the loss of CD4 T cells, the primary target of direct HIV infection. While HIV does not significantly infect $\mathrm{mDC}$ in vivo (11), mDCs are altered in function (12) and decreased in number (1317 ) in the blood in untreated people living with HIV (PLWH) and simian immunodeficiency virus (SIV)-infected macaques $(18,19)$. Increased HIV RNA viral loads and disease progression are associated with loss of blood $\mathrm{mDC}(13-16,18)$. There is some indication that $\mathrm{mDC}$ may be an important co-factor in the efficient infection of CD4 $\mathrm{T}$ cells as in vitro studies show they bind virus on their cell surface and are able to transfer virus to CD4 T cells in a mode called "trans" infection $(20,21)$ [reviewed in Manches et al. (22)].

Antiretroviral therapy (ART) has been developed to limit HIV replication and prevent the loss of CD4 T cells. Unfortunately, ART is not always efficacious as some PLWH fail to reconstitute their CD4 T-cell numbers and become susceptible to opportunistic infections. One component of ART failure may be a result of the incomplete restoration of blood $\mathrm{mDC}$ count and function. One can speculate that myeloid cells, and specifically $\mathrm{mDC}$, play a role in HIV persistence. First, plasma levels of two soluble myeloid cell surface molecules, CD14 and CD163, correlate with adverse events, co-morbidities, and disease progression in both ART-treated and treatment-naïve (TN) people living with HIV (PLWH) (23-31) and SIV-infected macaques (32). CD14 and CD163 are shed by myeloid cells (particularly monocytes) after binding to bacterial ligands. It is thought that this myeloid cell surface molecule shedding occurs, in part, because of the elevated levels of the gram-negative bacterial endotoxin, lipopolysaccharide (LPS), in the blood of
PLWH. Increased LPS and other bacterial components in the blood of PLWH (33-35) are hypothesized to be a result of increased gastrointestinal (G.I.) tract permeability in PLWH (36) [reviewed in Brenchley and Douek (37, 38)]. Second, generalized T-cell immune activation occurs with chronic HIV infections (39-42) and correlates with HIV disease progression. This immune activation is associated with ART failure, yet its causes remain unexplained. It is possible that $\mathrm{mDC}$, in close contact with $\mathrm{T}$ cells, play a role in such immune activation. Thus, due to their close association with $\mathrm{T}$ cells, and their changes in $\mathrm{PLWH}, \mathrm{mDC}$ may be important in sustaining generalized T-cell immune activation that occurs in PLWH. Third, Mycobacterium tuberculosis (MTB) is a major opportunistic infection (O.I.) in PLWH. While the incidence of MTB is significantly reduced after ART, by ca. sixty-five percent $(43,44)$, it is not completely eliminated and still occurs at higher frequencies worldwide in PLWH than in the population at large $(43,44)$. Studies in mice suggest that $\mathrm{mDC}$ are important for immune responses to and clearance of MTB [reviewed in Durai and Murphy (45)], and therefore, their decreased numbers may be a factor in MTB susceptibility PLWH. Thus, $\mathrm{mDC}$ loss or alterations may be related to the increased susceptibility to secondary infections in PLWH.

Our work, described herein, was designed to determine whether mDC gene expression is altered in untreated or ARTtreated PLWH. While the loss of CD4T cells has been the dominant explanation for the immune dysfunction that occurs during HIV infections, including susceptibility to O.I.s such as $\mathrm{MTB}$, defects in $\mathrm{mDC}$ may also play a role. Some limitations and/or failure of ART might be attributable to changes in $\mathrm{mDC}$ and/or myeloid cells.

\section{MATERIALS AND METHODS}

\section{Study Participants}

All participants included in this study provided written informed consent. This study was approved by either the Institutional Review Boards of the National Institute of Allergy and Infectious Diseases or the Vaccine and Gene Therapy Institute Florida (VGTIFL), as appropriate. In order to obtain a sufficient number of $\mathrm{mDC}$, apheresis was obtained from each donor. Participants were pre-screened for their ability to undergo apheresis. Each participant was required to be in good health and have within, or close to, normal levels of circulating CD4 T cells. Apheresis was performed for all subjects.

\section{Myeloid Dendritic Cell and Monocyte Purification}

mDCs were directly isolated from donors as follows: We identified $\mathrm{mDC}$ using the following markers: $\mathrm{CD} 1 \mathrm{c}^{+}, \quad \mathrm{HLA}-\mathrm{DR} \mathrm{R}^{\text {intermediate to high }}, \mathrm{CD} 11 \mathrm{c}^{\text {high }}, \mathrm{CD}^{-} 4^{-}$, $\mathrm{CD}_{1}{ }^{-}, \mathrm{CD}^{-}, \mathrm{CD}^{-} 23^{-}$, and BDCA $4^{-}$(summarized in Supplementary Figure 1). The leukapheresis product was elutriated (Elutra, Gambro) to separate myeloid cells from lymphocytes, according to the manufacturer's protocol $(46,47)$. The elutriated myeloid cells were then used for the separation of $\mathrm{mDC}$ and $\mathrm{CD} 14^{+}$monocytes by a magnetic 
bead-enrichment protocol (DC Enrichment Kit, Miltenyi) and platform (Automacs, Miltenyi) for the isolation of DC. Briefly, the elutriated myeloid cells were incubated with Fc receptor block and BDCA-4 antibody conjugated to magnetic beads for $15 \mathrm{~min}$ at $4^{\circ} \mathrm{C}$. Cells were washed and then centrifuged at 1,650 $\mathrm{rpm}$ for $3 \mathrm{~min}$. The cells were resuspended in wash buffer and depleted of BDCA-4+ plasmacytoid DCs by magnetic bead separation. The remaining cells were washed and incubated with a magnetic bead-conjugated CD19 antibody and a biotinconjugated CD1c antibody for $15 \mathrm{~min}$ at $4^{\circ} \mathrm{C}$. Cells were then washed and centrifuged for $3 \mathrm{~min}$ at 1,650 rpm and resuspended in wash buffer (PBS with 2\% BSA and $0.09 \%$ azide). The cells were depleted of $\mathrm{CD}_{19}{ }^{+} \mathrm{B}$ cells. The remaining cells were centrifuged and incubated with an anti-biotin antibody to capture $\mathrm{CD}_{1} \mathrm{c}^{+}$cells. In some cases, when elutriation did not result in cell fractions that were highly enriched for monocytic cells, as determined by an automated cell counter (Countess, Invitrogen), cells were further separated by Ficoll and then enriched by antibody-conjugated bead separation followed by FACS sorting with the same procedures as described for the elutriated-only product. This was performed for two samples. For all samples, monocytes were isolated from the cell fraction remaining after magnetic bead-conjugated antibody depletion of ${\mathrm{CD} 1 \mathrm{c}^{+}}^{+}$cells, B cells, and plasmacytoid DC, as per the manufacturer's protocol (Miltenyi).

It is known that using bead enrichment alone yields DC preparations that are contaminated with other cell types (48), and for this reason, we used a subsequent FACS purification step. The magnetic bead enriched mDCs or monocyte populations were further purified by fluorescence-activated cell sorting (FACS; Becton Dickinson, FACSARIA). Viable mDC, as measured by the viability dye, aqua (Invitrogen), were sorted on the basis of size (side scatter and forward scatter) and the following markers (obtained from BD Biosciences): CD11 $\mathrm{c}^{\text {high }}$, HLA$\mathrm{DR}^{\text {intermediate to high }}, \mathrm{CD}_{14}^{-}, \mathrm{CD}_{2} 23^{-}, \mathrm{CD}^{-}, \mathrm{CD} 56-$, and $\mathrm{CD}^{-} 9^{-}$. Monocytes were sorted on the basis of size (side scatter and forward scatter), viability (aqua vs. side scatter), and the following markers: HLA-DR intermediate to high $, \mathrm{CD} 14^{\mathrm{hi}}, \mathrm{CD}^{-}$, $\mathrm{CD}^{-} 6^{-}, \mathrm{CD}_{123^{-}}$, and $\mathrm{CD} 19^{-}$(Supplementary Figure 1). We showed that monocytes were confirmed to be $\geq 97 \%$ pure by postsort analysis and estimate the $\mathrm{mDC}$ had the same level of purity, although there were not sufficient mDCs to analyze by post-sort analysis. Cells were sorted directly into RLT buffer (guanidinium thiocynate) with $1 \% \beta$-mercaptoethanol (Qiagen) and stored at $-80^{\circ} \mathrm{C}$ until RNA isolation. All cells were sorted as replicates, in at least duplicates.

\section{mRNA Extraction and cRNA Generation}

RNA was extracted from RLT Buffer (Qiagen)-treated mDC using the RNeasy Micro kit (Qiagen), according to the manufacturer's protocol. Total RNA was checked for quantity and quality using a NanoDrop 2000c spectrophotometer (Thermo Fisher Scientific) and Experion automated electrophoresis system (Bio-Rad Laboratories). Samples that were not of sufficient quality and/or quantity were not further studied. mRNA from each sample was amplified using the MessageAmp II aRNA Amplification kit (Ambion) according to the manufacturer's protocol. This involved oligo DT primers and optimized MMLV RT, T7 RNA polymerase, and biotinylated nucleotides.

\section{Microarray Analyses}

Subsequently, $750 \mathrm{ng}$ of the biotinylated amplified cRNA was hybridized to the HumanRef- 8 v3.0 or Human Transcriptome (HT)12_V4_Beadchip Microarrays (Illumina) at $58^{\circ} \mathrm{C}$ for $20 \mathrm{~h}$ and then quantified using the iScan System (Illumina).

\section{Statistical Analyses}

The statistical analysis of the microarray data was performed essentially as described (49). Analysis of the Genome Studio output data was conducted using the $\mathrm{R}$ statistical language ( $\mathrm{R}$ Development Core Team) and software packages from Bioconductor (50). First, arrays displaying unusually low median intensity or low correlation relative to the bulk of the arrays were discarded from the rest of the analysis. Quantile normalization was applied followed by a $\log _{2}$ transformation. Some samples were acquired at different times, using different versions of the HT gene arrays. For this reason, batch correction was employed to normalize for interarray variability. Batch effect subtraction was performed using the ComBat procedure (51). The LIMMA package (Bioconductor) (52) was used to fit a linear model to each probe and to perform a (moderated) Student's $t$ test on various differences of interest.

Ingenuity pathways analysis (IPA, Qiagen) and gene set enrichment (GSEA) were used to identify pathways altered in the samples being compared. Two-dimensional scaling analysis was done in Bioconductor. The expected proportions of false positives, the false discovery rates (FDR), were estimated from the unadjusted $p$-value using the Benjamini and Hochberg method (53). The microarray data are available through the National Center for Biotechnology Information Gene Expression Omnibus (GEO) under accession no. GSE139559.

\section{Quantification of Intracellular IL-1 $\alpha$ and Phosphorylated p38 and IkK $\gamma$}

Peripheral blood mononuclear cells (PBMC) from study subjects were isolated by density gradient centrifugation (Histopaque, GE Healthcare) of aphereses obtained from TN HIV-infected or HIV-uninfected individuals. PBMC were stained with the following cell surface molecules: HLA-DR APC-Cy7 (BD Biosciences), CD11c APC (BD), CD14 Pacific Blue (BD), CD3 PerCP-Cy5.5 (BD), and CD19 ECD (Beckman Coulter) for $30 \mathrm{~min}$ and washed twice in FACS buffer ( $2 \%$ fetal bovine serum in PBS). The samples were then resuspended in complete media (RPMI 1640) and stimulated with interleukin-1 (IL-1; $10 \mathrm{ng} / \mathrm{ml}$; $\mathrm{R} \& \mathrm{D}$ Systems) for $15 \mathrm{~min}$ at $37^{\circ} \mathrm{C}$. Following the incubation, the samples were centrifuged at 1,800 rpm for $5 \mathrm{~min}$ at RT and then fixed with pre-warmed BD Cytofix buffer (BD Biosciences) for $10 \mathrm{~min}$ at $37^{\circ} \mathrm{C}$. The fixed samples were then permeabilized in cold BD Phosphoflow ${ }^{\mathrm{TM}}$ Perm Buffer III (BD Biosciences). Samples were washed in FACS buffer and then stained with BD Phosphoflow $^{\mathrm{TM}}$ phosphorylation intracellular p38-P and I $\mathrm{K} \gamma$ $\mathrm{P}$ antibodies (BD Biosciences). After two additional washes with FACS buffer, the samples were analyzed by flow cytometry using an LSR II (BD) and DIVA software. mDCs were identified by 
TABLE 1 | Study participants for $\mathrm{mDC}$ isolations.

\begin{tabular}{|c|c|c|c|c|c|c|c|}
\hline HIV status & Age (years) & Gender & Treatment & $\begin{array}{c}\text { Estimated time } \\
\text { since } \mathrm{HIV} \pm \text { (years) }\end{array}$ & $\begin{array}{l}\text { Time since } \\
\text { ART (years) }\end{array}$ & $\begin{array}{l}\text { Viral RNA } \\
\text { copies/ml }\end{array}$ & CD4 T cells $/ \mu$ I \\
\hline HIVp1 & 28 & $M$ & ART & 2 & 2 & $<50$ & 447 \\
\hline HIVp2 & 52 & $M$ & ART & 15 & 13 & 392 & 654 \\
\hline HIVp3 & 51 & $\mathrm{~F}$ & TN & 12 & NA & 5,970 & 641 \\
\hline HIVp4 & 41 & $M$ & ART & 12 & 6 & $<50$ & 619 \\
\hline HIVp5 & 21 & $\mathrm{M}$ & TN & 1 & NA & 304,742 & 513 \\
\hline HIVp6 & 52 & $M$ & TN & 20 & NA & 19,998 & 430 \\
\hline HIVn1, 2, 3, 4 & $\S$ & $\S$ & NA & NA & NA & NA & * \\
\hline
\end{tabular}

The cohort included antiretroviral therapy (ART)-treated and treatment-naïv (TN) (in bold) people living with HIV (PLWH) as well as HIV-uninfected persons. HIVp, HIV positive; HIVn, HIV negative; NA, not applicable; §, unavailable; *within normal ranges for CD4 T cells.

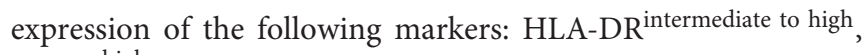
$\mathrm{CD} 11 \mathrm{c}^{\text {high }}, \mathrm{CD}_{14}^{-}, \mathrm{CD}^{-}, \mathrm{CD}^{-} 9^{-}, \mathrm{CD}^{-} 6^{-}$, and $\mathrm{CD} 123^{-}$. Analyses were performed using Flow Jo version 10 (Tree Star) to assess IL- $1 \alpha$ levels, and p38 and IкK $\gamma$ phosphorylation levels after flow cytometry gating on $\mathrm{mDC}$ populations.

Intracellular IL-1 $\alpha$ expression was determined by intracellular staining with a PE-conjugated antibody to IL-1 $\alpha$ (BD Pharmingen). PBMCs were stimulated with CL097 $(1 \mu \mathrm{g} / \mathrm{ml}$; a TLR 8 ssRNA analog; Invivogen) or LPS (100 ng/ml; SigmaAldrich) for $16 \mathrm{~h}$. Cells were stained with antibodies to the aforementioned cell surface molecules for $30 \mathrm{~min}$ and washed twice in FACS wash buffer, after centrifugation at 1,800 rpm for 5 min followed by a fixation in $2 \%$ PFA in PBS. Then cells were permeabilized by a wash with $0.05 \%$ saponin in PBS followed by centrifugation at $1,800 \mathrm{rpm}$ for $5 \mathrm{~min}$. Cells were then stained with IL- $1 \alpha$ antibody in PBS with $0.05 \%$ saponin for $30 \mathrm{~min}$ at room temperature. Cells were then washed twice in FACS wash buffer and then fixed in 2\% PFA in PBS. Sample data were collected as described above.

\section{RESULTS}

\section{Isolation of mDC From PLWH and HIV-Uninfected Study Participants}

The participants are a cross section of HIV-infected persons who were seen at the Vaccine Research Center Clinic, NIAID, $\mathrm{NIH}$ (Bethesda, MD) and who were infected with HIV for times ranging from an estimated 1 to 20 years and who met the criteria of having within, or close to, normal levels of CD4 T cells in the blood, i.e., $\sim 500-1,500 \mathrm{CD} 4 \mathrm{~T}$ cells/ $\mu$ l (Table 1). Three of the six HIV-infected persons were untreated, while the others received ART regimens for times ranging between 2 and 13 years. The estimated time since HIV infection was between 1 and 20 years for the TN participants and between 2 and 15 years for the ART-treated participants. All ART-treated PLWH had been treated at least 2 years before enrolling in this study. Two of the ART-treated participants were virally suppressed, $<50$ plasma viral RNA copies/ml, and one ART-treated individual had a plasma viral RNA load of $\sim 400$ copies $/ \mathrm{ml}$, which is considered a relatively low viral load. Since only one time point was examined, it is not known whether the ca. 400 copies/ml represents an
TABLE 2 | Strategy for the isolation of mDC from PLWH and HIV uninfected persons.

\begin{tabular}{|c|c|c|}
\hline Cell surface marker & Enrichment & FACS \\
\hline $\mathrm{CD}_{1 \mathrm{C}^{+}}$ & $x$ & \\
\hline BDCA-4- & $x$ & \\
\hline CD19- & $x$ & \\
\hline HLA-DR intermediate-high & & $x$ \\
\hline $\mathrm{CD}_{11 \mathrm{C}^{+}}$ & & $x$ \\
\hline CD14- & & $x$ \\
\hline Lin $\left(\mathrm{CD}^{-}, \mathrm{CD}^{-} 6^{-}, \mathrm{CD}^{-} 9^{-}, \mathrm{CD}^{-} 3^{-}\right)$ & & $x$ \\
\hline
\end{tabular}

ongoing low level of viral replication or a "viral blip." Viral blips are known to occur in $\sim 20 \%$ of ART-treated PLWH (54).

Of the untreated HIV-infected participants, plasma viral RNA loads were of a wide range, from 6,000 to 300,000 copies $/ \mathrm{ml}$ (Table 1). It is generally accepted that long-term non-progressors (LTNPs) are PLWH who have been HIV infected for $\geq 7$ years and maintain CD4 T cells $\geq 500$ cells/ $\mu$ l of blood [reviewed in Gurdasani et al. (55)]. Subject HIVp3 had been infected for an estimated 12 years and had CD4 T-cell levels of ca. 640 cells/ $\mu \mathrm{l}$ and, thus, is considered an LTNP. Participant HIVp6 was HIV infected for over 20 years and had CD4 T cells of 430 cells/ $\mu \mathrm{l}$ and, thus, is not considered an LTNP. The third untreated HIVinfected participant, HIVp5, was infected for only 1 year. In addition to the HIV-infected participants, four HIV uninfected healthy subjects, with CD4 T-cell levels within the normal range, whose blood was available through the NIH Clinical Center, were also studied as controls (Table 1). All individuals were subjected to apheresis.

As mDCs are sensitive to cryopreservation, we obtained mRNAs from freshly isolated mDCs as well as from monocytes, as described (see Materials and Methods section). We identified $\mathrm{mDC}$ using the following markers: $\mathrm{CD}_{1}{ }^{+}$, HLA$\mathrm{DR}^{\text {intermediate to high }}$ CD11c $\mathrm{c}^{\text {high }}, \mathrm{CD}_{14}^{-}, \mathrm{CD}^{-} 9^{-}, \mathrm{CD}_{123^{-}}$, $\mathrm{CD}^{-} 6^{-}$, and BDCA $4^{-}$(Table 2 and Supplementary Figure 1). Monocytes were identified by the following markers: $\mathrm{CD}_{1}{ }^{-}$, HLA-DR ${ }^{\text {intermediate to high }}$, CD14 ${ }^{\text {high }}, \mathrm{CD}^{-}{ }^{-}, \mathrm{CD}_{123^{-}}, \mathrm{CD} 56-$, and BDCA-4 $4^{-}$(Supplementary Figure 1). We isolated mRNA 
A

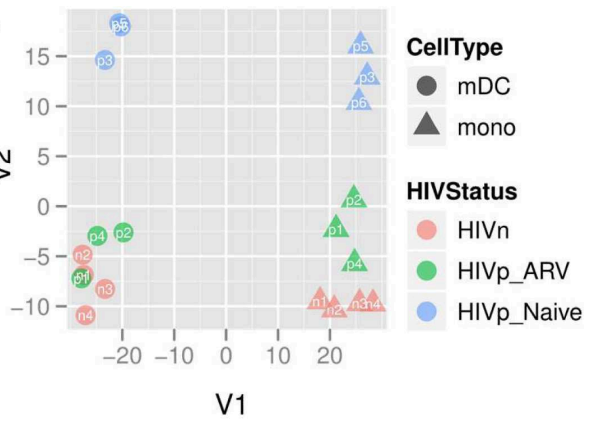

B

HIV+ Naive vs HIV-

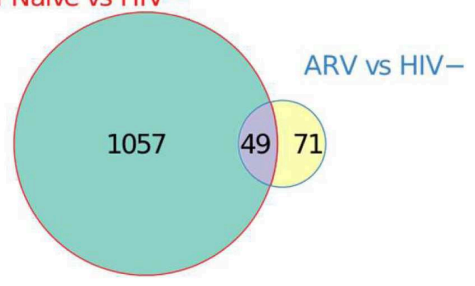

D

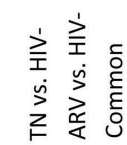

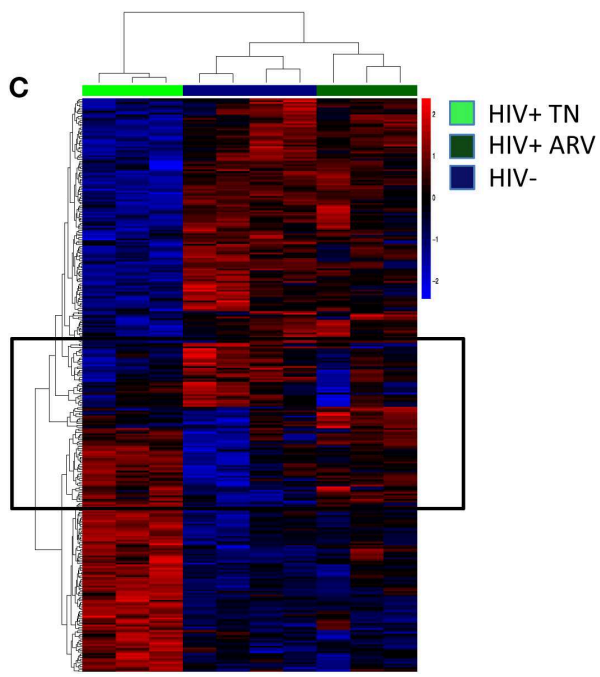

FIGURE 1 | Myeloid dendritic cells (mDCs) from treatment-naïve (TN) and antiretroviral (ARV)-treated people living with HIV (PLWH) have a different gene transcription compared to mDCs from HIV-uninfected individuals. (A) Principal component analysis of the gene expression profiles for the top-most variable genes between mDCs and monocytes from TN PLWH, ARV-treated PLWH, and HIV-uninfected individuals. (B) The Venn diagram indicates the number of common and unique genes (|FC| $>2$ and $p<0.05$ ) between the mDC contrasts from PLWH and HIV-uninfected persons. (C) Heatmaps of differentially expressed genes of mDC from treatment-naive (TN) or ARV-treated PLWH. Differentially expressed genes with $|F C|>2$ and $p<0.05$ are shown. Highlighted on the heatmap, indicated by a box, are those genes commonly altered in mDC from TN and ARV-treated PLWH compared to HIV-uninfected persons. (D) Pathway alterations in mDC from TN and ARV-treated PLWH compared to mDC from HIV uninfected persons. Ingenuity pathway analysis (IPA), as described in the Materials and Methods section, was used to identify those pathways enriched in the differentially expressed genes in each contrast. The complete list of pathways associated with these contrasts is provided in the Supplementary Materials, Supplementary Figure 2. ARV, antiretroviral therapy; HIVn, HIV negative; HIVp_Naive, HIV positive, treatment naïve; HIVp_ARV, HIV positive, antiretroviral-treated.

from these purified cells, generated cRNA libraries, and performed gene expression array analyses.

\section{Altered Gene Expression in mDC From Untreated and ART-treated PLWH}

We compared the gene expression profiles of $\mathrm{mDC}$ and monocytes from treatment-naïve (TN) PLWH, ART-treated PLWH, and those from HIV-uninfected individuals. The principal component analysis (PCA) describes the variation in gene expression between samples of interest. Using the PCA, we found that cell type-specific gene expression represented the greatest variation between the samples. This is graphically represented in PC1 (or the $\mathrm{x}$ axis) in Figure 1A, with mDCs and monocytes separating from each other, for all individuals (Figure 1A). Other gene expression variations between samples are accounted for in PC2 (or the y axis). Samples grouped together based on HIV treatment status in PC2. mDCs and monocytes from TN PLWH grouped together in PC2, as did mDCs and monocytes from ART-treated PLWH, and as did those from HIV-uninfected persons (Figure 1A). However, mDCs and monocytes from TN individuals had the greatest divergence from all of the other groups. For example, mDCs and monocytes from ART-treated individuals clustered more closely to those from HIV-uninfected individuals than those from TN PLWH. The transcriptional profile for mDCs and monocytes from ARTtreated HIV-infected individuals, however, segregated distinctly from HIV-uninfected individuals (Figure 1A).

We performed a differential gene expression (DEG) analysis between $\mathrm{mDC}$ from $\mathrm{TN}$ or ART-treated PLWH to those from HIV-uninfected persons (using a supervised analysis). We found that 1,106 genes were differentially expressed between mDCs from TN PLWH compared to those of HIV-uninfected individuals (FC, fold change $\geq 2, p \leq 0.05$; Figure 1B). We also found that 120 genes were differentially expressed in mDCs 
from ART-treated HIV PLWH compared to those of HIVuninfected individuals (Figure 1B). Of the 120 genes altered in mDCs from ART-treated PLWH compared to those of
HIV-uninfected individuals, 71 of these were unique to ART treatment, while 49 of these were shared with mDCs from TN PLWH (Figure 1B).

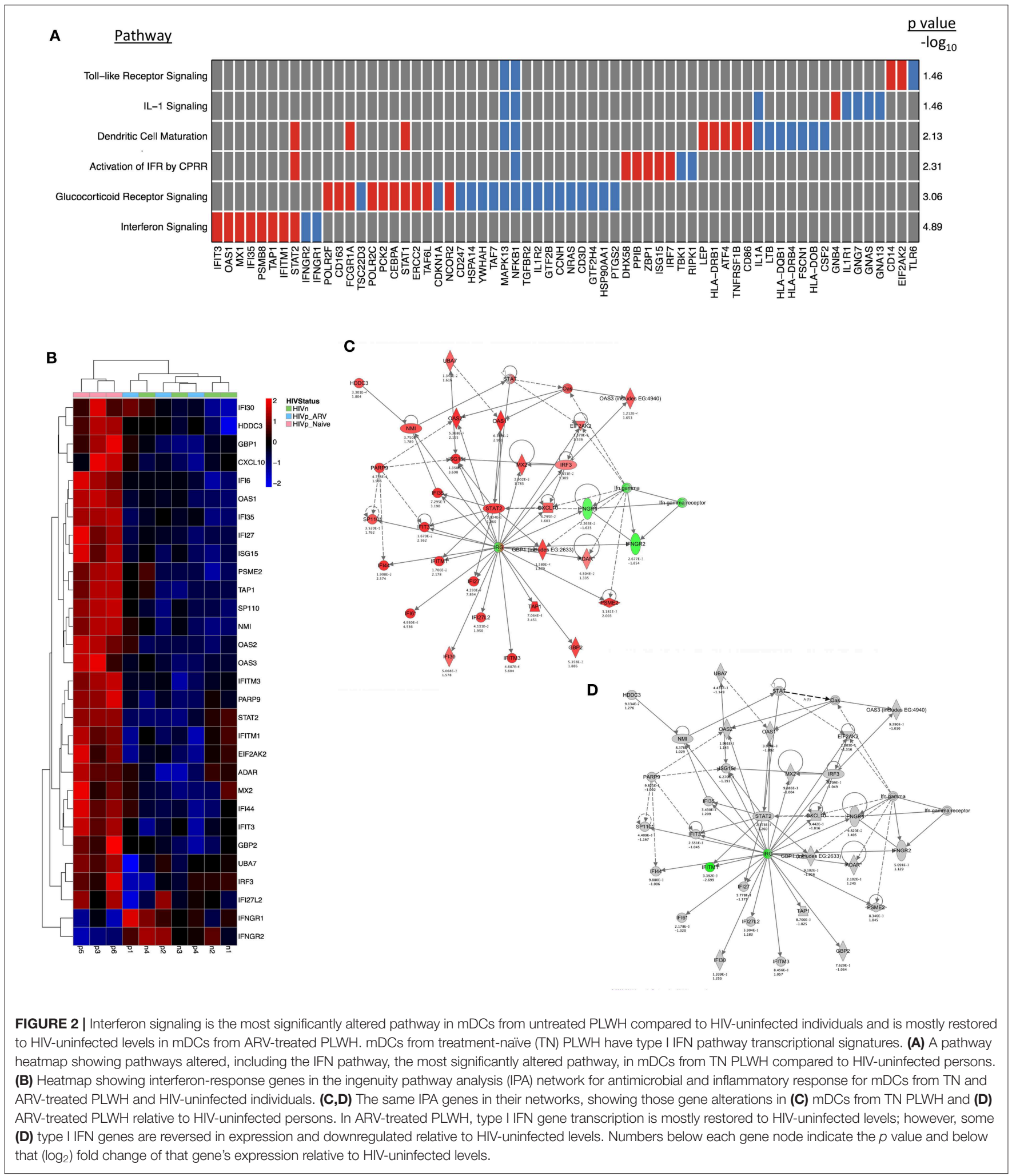




\section{mDC Biological Pathways Are Altered in Untreated and ART-Treated PLWH}

When evaluating the differentially expressed genes in the mDCs from TN PLWH compared to those from HIV-uninfected persons, we found that the mDCs from ART-treated PLWH grouped more closely to the mDCs from HIV-uninfected individuals (Figure 1C). However, mDCs from ART PLWH formed a distinct group or branching from HIV-uninfected individuals, as depicted in the heatmap shown (Figure 1C). The ART profile was more akin to the HIV-uninfected profile, but there are groups of genes that differed from those of HIVuninfected individuals, many of which were in common with those of TN HIV-infected persons (Figure 1C). This was also the case for the $\mathrm{CD}_{14}^{+}$monocytes (data not shown). We then determined whether the genes that changed in the three groups were included in specific biological pathways. We used the ingenuity pathways analysis (IPA) database to identify such pathways. The most highly represented pathway alteration in mDCs in TN PLWH relative to HIV-uninfected persons was the interferon pathway (Figure 1D and Supplementary Figure 2). We also found significant alterations in other pathways such as the viral nucleotide excision repair and mechanisms of viral exit from host cell pathways. There were also alterations in the antigen processing and presentation and MTOR pathways as well as in the IL-1 signaling pathway (summarized in Figure 1D and Supplementary Figure 2).

In mDCs from ART-treated PLWH, the IL-4 and IL-10 pathways were altered relative to HIV-uninfected persons, and these were not significantly altered in TN PLWH (Figure 1D and Supplementary Figure 2). Pathway alterations shared between mDCs from ART-treated and TN PLWH included the FC receptor-mediated endocytosis pathway and antigen processing and presentation (Figure 1D). Thus, while the majority of pathway changes in $\mathrm{mDC}$ appeared to be reversed by ART, there were some pathways that were only found in the mDCs from ART-PLWH and some pathways that were shared between the mDCs from ART and TN PLWH relative to HIV-uninfected individuals (Figure 1D and Supplementary Figure 2).

\section{A Type I IFN Transcriptional Signature in mDCs From TN PLWH Is Mostly Reversed by ART}

We observed that mDCs from TN HIV-infected individuals had profound transcriptional upregulation of a type I interferon (IFN) response (Figures 2A-C). When we scrutinized networks of IFN-inducible genes of mDCs from TN PLWH, we found a significant induction of many of the IFN-inducible genes (Figures 2A-C) including several that are components of the innate cell intrinsic antiviral machinery (MX1, OAS1, IFIT3). STAT1 and STAT2, which activate type I IFN transcriptional networks, with STAT1 also involved in type II IFN responses, were uniformly upregulated in $\mathrm{mDC}$ from TN PLWH (Figures 2A-C). Surprisingly, other components of the IFN $\gamma$ (type II IFN) pathway such as IFN gamma receptor 1 (IFN $\gamma \mathrm{R} 1)$ and 2 (IFN $\gamma \mathrm{R} 2)$ were slightly downmodulated in mDCs from TN HIV-infected subjects (Figures 2A,C).
The type I IFN pathway in the mDCs from ART-treated PLWH was similar to the mDCs from HIV-uninfected persons. However, the mDCs from ART-treated PLWH did not exhibit complete restoration of the type I IFN pathway to expression levels observed in HIV-uninfected individuals (Figures 2B,D). Three genes (IFITM1, IRF7, and IRF9), which are involved in regulation and transcriptional activation of interferon responses, were all reversed in expression change, and were downregulated relative to that of $\mathrm{mDC}$ from $\mathrm{HIV}$-uninfected individuals (Figures 2B,D).

\section{IL-1 Signaling Is Suppressed in mDCs From TN PLWH}

We identified transcriptional downmodulation of the IL-1 pathway in TN HIV-infected individuals (Figures 3A-C). We found several genes that encode cytokine receptors belonging to the interleukin 1 receptor family, including IL1RA, and IL1R2 as well as IL1A, itself, were downregulated in mDCs from TN PLWH compared to HIV-uninfected individuals (Figures 3A,B). The IL-1 signaling pathway plays a critical role in response to microbial infection [reviewed in Mayer-Barber and Yan (56)]. In order to validate some of the transcriptional changes seen, we looked at IL- $1 \alpha$ protein levels in activated mDC TN PLWH (Figures 4A-C). We sought to determine whether $\mathrm{mDCs}$ from TN HIV-infected individuals were impaired in IL-1 $\alpha$ production after microbial stimulation or in IL-1 signaling pathways downstream of IL- $1 \alpha$ stimulation. In order to address this, we first tested mDCs obtained from $\mathrm{TN}$ PLWH or HIV-uninfected persons, before or after microbial exposure in vitro. We measured intracellular IL-1 $\alpha$ production in mDCs from HIV-uninfected individuals and compared this to that of TN HIV-infected individuals. We found no significant difference in basal levels of IL-1 $\alpha$ protein expression (Figure 4A). However, upon stimulation with a single-stranded RNA tolllike receptor (TLR) 7/8 agonist, CL097 ( $p<0.01$ ), or TLR4 (and CD14) agonist LPS ( $p<0.001$ ), we found a statistically significant decline in IL- $1 \alpha$ production among HIV-infected $\mathrm{TN}$ individuals compared to that of HIV-uninfected individuals (Figure 4A).

IL- $1 \alpha$ stimulation activates the NF- $\kappa$ B pathway, which is essential for innate immune cell function [reviewed in Caamano and Hunter (57) and Dorrington and Fraser (58)]. Activation of NF- $\kappa$ B requires phosphorylation of p38 (MAPK) and I $\kappa$ K. Thus, we quantified levels of phosphorylated p38 and IкK $\gamma$ after IL- $1 \alpha$ stimulation of $\mathrm{mDC}$, to determine whether activation of the NF$\kappa \mathrm{B}$ pathway by IL- $1 \alpha$ stimulation was impaired in $\mathrm{mDC}$ from TN PLWH as we had observed in gene transcription. Following stimulation of mDCs from HIV-infected TN individuals with IL$1 \alpha$, we also observed a statistically significant suppression of p38 MAPK activation and NF- $\kappa \mathrm{B}$ activation by I $\kappa \mathrm{K} \gamma$ phosphorylation between HIV-uninfected and TN HIV-infected individuals ( $p=$ 0.052 and $p=0.005$, respectively) (Figures 4B,C). Similarly, one previous study demonstrated suppressed I $\kappa \gamma \gamma$ phosphorylation after TLR ligand stimulation in DCs from healthy individuals in an HIV plasma-transfer model (12). We found that mDCs from chronic TN HIV infections have suppressed IL- $1 \alpha$ activation in 
A

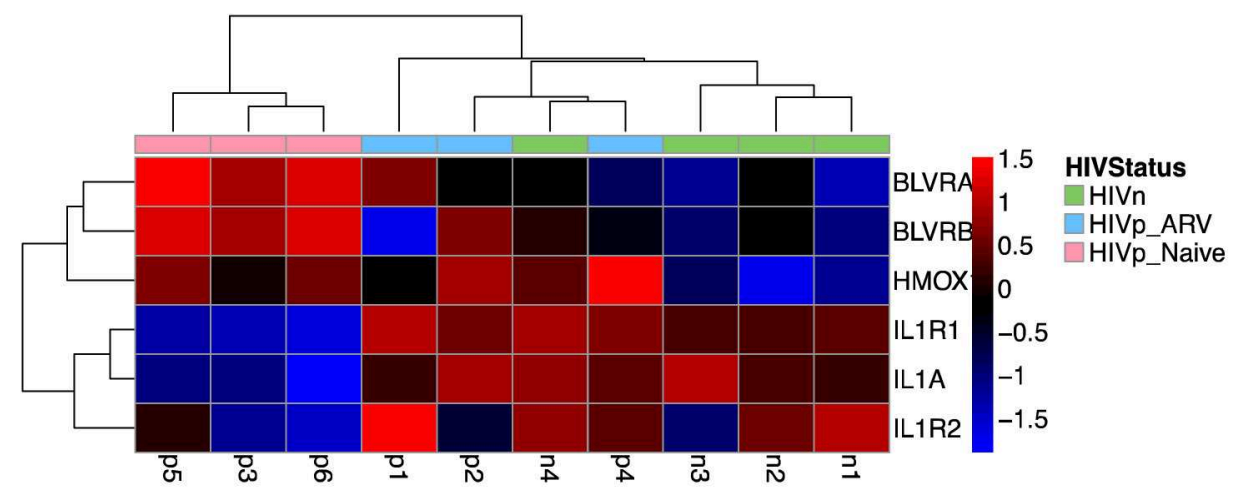

B

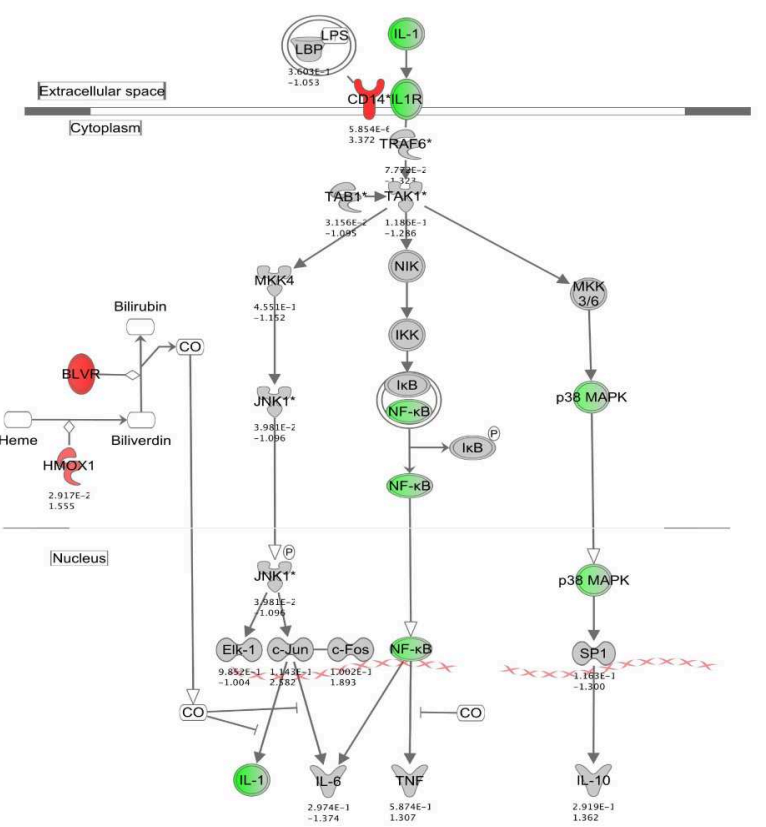

C

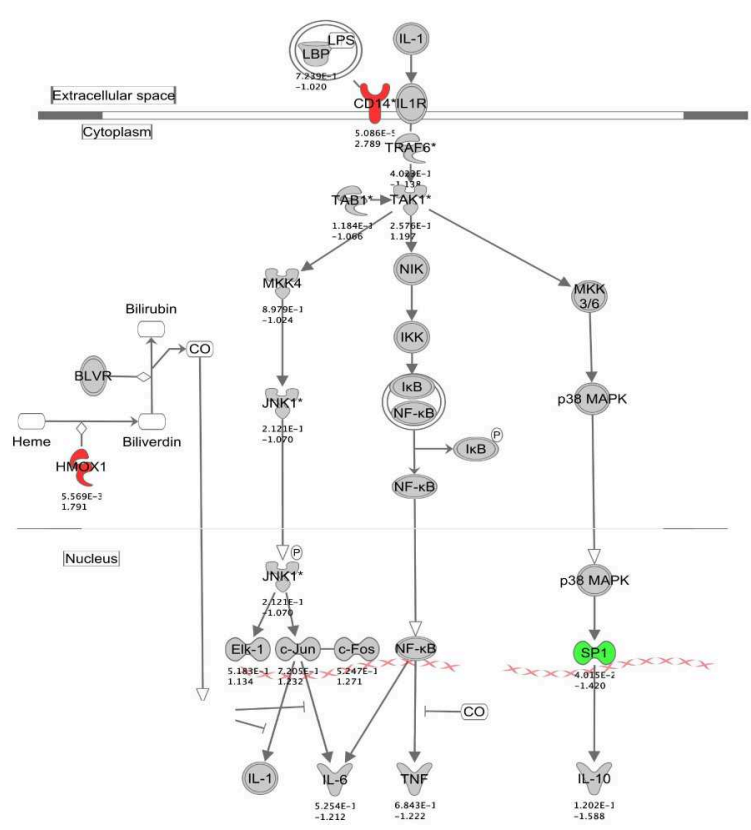

FIGURE 3 | The IL-1 signaling pathway is transcriptionally suppressed in $\mathrm{mDC}$ from treatment-naive PLWH. (A) Heatmap and (B) network illustrating key IL-1 pathway genes and their modulators. $(\mathbf{A}, \mathbf{B}) \mathrm{IL}-1 \alpha$ and its receptors are transcriptionally suppressed in mDCs from TN PLWH compared to ARV-treated or HIV-uninfected persons. (B,C) Negative regulators of IL-1 signaling, including hemoxygenase (HMOX-1) and CD14, components of the IL-10 pathway, are (B) upregulated in mDCs from TN PLWH. (C) In mDCs from ARV-treated PLWH, levels of suppressors of IL-1 signaling are not completely restored to levels of mDCs from HIV-uninfected persons. (B,C) Shown is the ingenuity pathway analysis (IPA) pathway, showing both IL-1- and IL-10-associated genes. Numbers below each gene node indicate $p$ value and below that $\left(\log _{2}\right)$ fold change of that gene's expression relative to HIV-uninfected levels.

response to microbial stimulation and an impaired IL-1 pathway in response to IL-1 $\alpha$ stimulation (Figures $4 \mathrm{~A}-\mathrm{C}$ ).

\section{IL-1 Signaling Pathway Is Mostly Restored in mDCs From ART-Treated PLWH}

Three known endogenous suppressors of the IL-1 pathway, Biliverdin A and B (BLVRA and BLVRB) and hemoxygenase1 (HMOX-1) are associated with the IL-10 pathway. All three were upregulated in TN and ART-treated PLWH compared to HIV-uninfected individuals (Figures 3A,C). Unlike the IL-1 receptor family genes in $\mathrm{mDCs}$ from ART-treated individuals that were like (grouped with) HIV-uninfected individuals in expression patterns (Figure 3A), the BLVR genes, and most significantly, the HMOX-1 gene expression, were more akin to mDCs from TN PLWH than from HIV-uninfected persons (Figures 3A,C). Therefore, ART is mostly reversing the IL-1 pathway gene transcription to HIV-uninfected levels, but not all of the suppressors of the IL-1 pathway, in mDCs. 

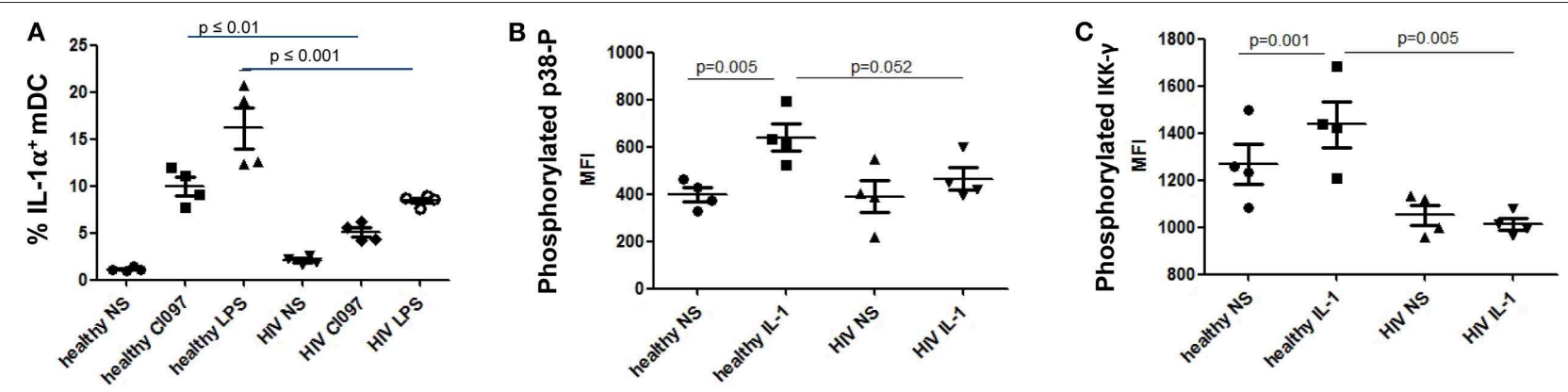

FIGURE 4 | Diminished interleukin-1 (IL-1 $\alpha$ ) production and suppressed NF-кB pathways in mDCs from treatment-naïve PLWH after IL-1 $\alpha$ or microbial stimulation. Impaired (A) IL-1 $\alpha$ production following microbial stimulation of mDCs from untreated PLWH. (B) IL-1-induced signaling in mDCs from untreated PLWH show decreased NF-кB activation as indicated by (B) p38 phosphorylation and (C) IKK $\boldsymbol{\gamma}$ phosphorylation. Phosphorylated p38 and IKK $\gamma$ were measured by flow cytometry, and the mean fluorescence intensity (MFI) of the specific antibodies are reported for $\mathrm{mDC}$, as described in the Methods and Materials section. CL097, a TLR 7/8 agonist. IL-1 refers to IL- $1 \alpha$-stimulated cells, as described in the Materials and Methods section. NS, no stimulation; LPS, lipopolysaccharide.

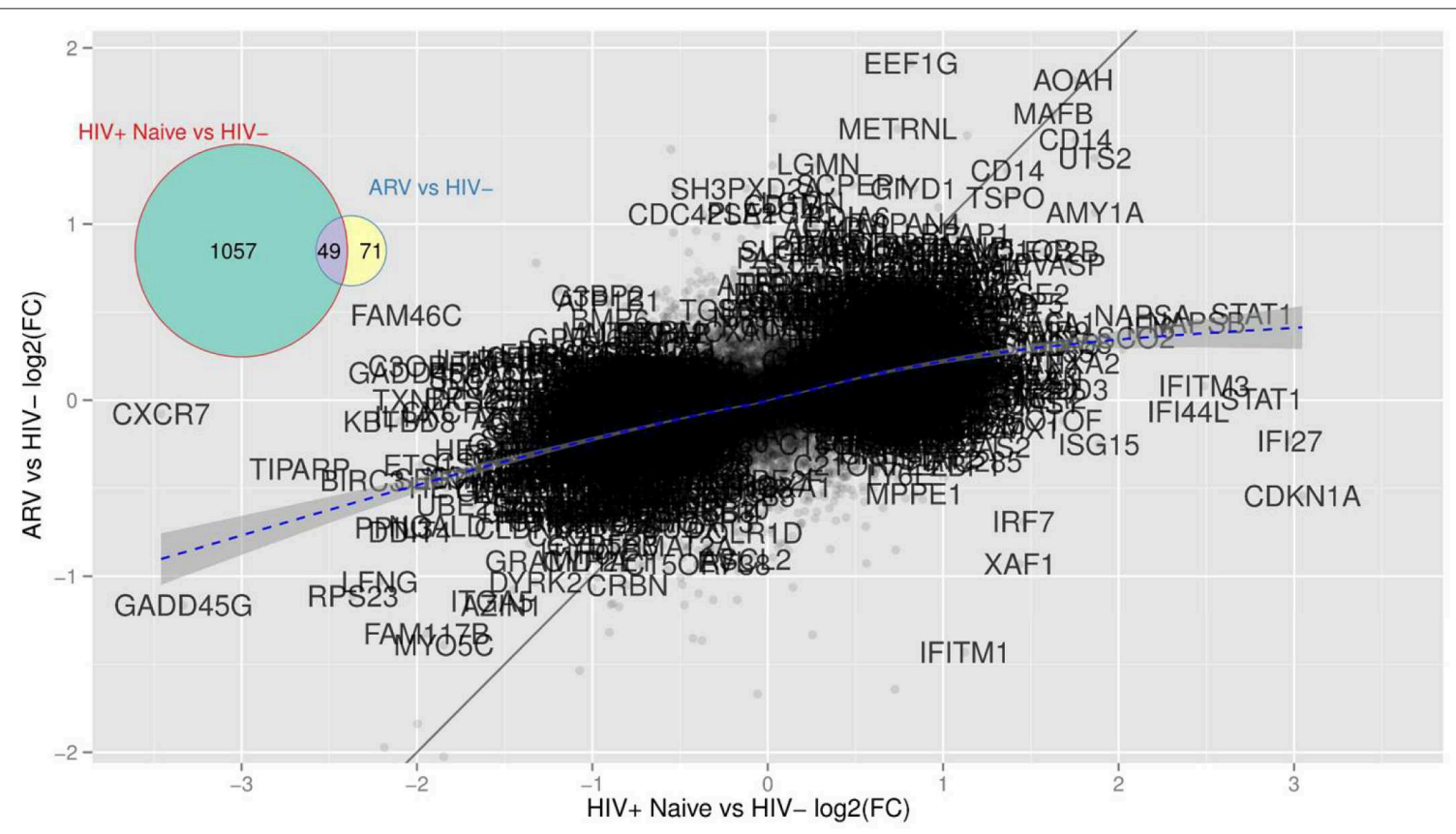

FIGURE 5 | mDCs from TN PLWH have transcriptional alterations not restored in mDCs from ARV-treated PLWH to HIV-uninfected levels. This scatterplot compares mDC gene expression from TN or ARV-treated PLWH relative to HIV-uninfected persons expressed as (log 2$)$ fold changes. There are far more genes with high fold changes in the TN than in the ARV group, indicating that mDCs from ARV-treated PLWH is closer to the HIV-uninfected group. There are genes "maintained," i.e., HIV-elicited genes that are unaffected by the therapy (AOAH, MAFB, CD14, all those close to the identity line or "common" genes) and genes whose differential expression is strongly suppressed by the therapy (all those close to the $x$-axis and, therefore, unique to TN PLWH), and those that are an effect of the therapy alone (close to the $y$-axis and unique to ARV). A gene like IFITM1 is reversed by therapy as it lies close to the $y=-x$ line.

\section{mDC Gene Transcription Including CD14 Is Not Restored by ART in PLWH and Indicates Altered Myeloid Cell Differentiation Pathways}

Similar to HMOX-1, a gene that was altered in mDCs from both TN and ART PLWH relative to HIV-uninfected individuals, we found that there were other genes commonly altered in HIV infection relative to HIV-uninfected persons. We examined those genes commonly altered in both TN and ART-treated
PLWH. The multidimensional scaling plot (MDS) (Figure 5) shows those genes commonly altered in mDCs from untreated and ART-treated PLWH as well as those not restored to HIV-uninfected levels with ART treatment. Strikingly, there exists a group of genes that are commonly upregulated and relatively unaffected in expression levels in TN and ART-treated PLWH. Some of the genes included CD14, acyloxyacyl hydrolase (AOAH), and MAFB (V-maf musculoaponeurotic fibrosarcoma oncogene homolog B). A gene such as IFITM1 is upregulated in mDCs from TN PLWH but downregulated in ART-treated 
TABLE 3 | List of genes whose transcription is commonly altered in mDCs from TN and ART-treated PLWH relative to HIV-uninfected persons.

\begin{tabular}{|c|c|}
\hline AAMP & POLR1D \\
\hline CECR5 & FAM109A \\
\hline STAB1 & BECN1 \\
\hline LRPAP1 & SEPT3 \\
\hline GTPBP8 & COASY \\
\hline CYP2E1 & NT5DC3 \\
\hline SLC2A9 & SFRS5 \\
\hline HK3 & MAFB \\
\hline MFSD7 & CENTD2 \\
\hline ZNF362 & AFF3 \\
\hline DGCR8 & NCALD \\
\hline EMILIN2 & TBC1D9B \\
\hline SFRS6 & CKAP4 \\
\hline HLA-DRB5 & MGAT4B \\
\hline HSPC111 & C1QB \\
\hline $\mathrm{AOAH}$ & RIOK1 \\
\hline HLA-DRB1 & MYO5C \\
\hline PRPF31 & TOMM7 \\
\hline SYTL3 & ARMCX1 \\
\hline CD163 & TSPO \\
\hline FAM117B & GIYD1 \\
\hline CD14 & FAM89A \\
\hline GRK6 & TSPAN4 \\
\hline ARS2 & ATP6V0B \\
\hline WAC & \\
\hline
\end{tabular}

PLWH compared to HIV-uninfected individuals (Figure 5). The complete set of 49 genes not restored by ART is shown (Table 3).

The genes were commonly altered in $\mathrm{mDC}$ from ART-treated and TN HIV-infected persons mapped to myeloid cell lineage and differentiation (Supplementary Figure 3), using GSEA analysis, which annotates genes according to modules (datasets annotated by function and coordinated expression). The modules commonly altered in mDC from TN and ART-treated PLWH were (1) myeloid lineage and (2) inflammation I and (3) inflammation II (Supplementary Figure 3). Prominently, some of those genes coordinately upregulated are those most classically associated with a monocyte/macrophage lineage including CD14, CD163, C1QB, and MAFB, and inflammatory response, such as AOAH (Figure 6 and Supplementary Figure 3), also associated with LPS response, as further discussed in the Discussion section. Overall, these results indicate that ART does not completely return transcription in $\mathrm{mDCs}$ from ART PLWH to levels seen in HIV-uninfected people.

\section{Summary}

Our data analyzing $\mathrm{mDC}$ gene expression indicated that two major pathways were mostly, but not completely, reversed by ART. These pathways are the IL-1 and type I IFN pathways. Surprisingly, some components of the type I IFN pathway were transcriptionally downregulated in mDCs from ART PLWH compared to HIV-uninfected persons. There were transcriptional changes common to mDCs of ART-treated and TN PLWH. Those genes mapped to myeloid cell differentiation and inflammation pathways and included $\mathrm{AOAH}$, and to genes classically associated with a monocyte/macrophage lineage and included CD14, C1QB, CD163, and MAFB. Since recent data from others indicate that there is a subset of $\mathrm{mDCs}$ that express these RNA transcripts classically associated with monocyte/macrophage, further studies will need to be done to determine whether the changes we observe are due to alterations in monocytes/macrophages in PLWH that render them more phenotypical like mDCs or expansion of the newly delineated $\mathrm{mDC}$ "inflammatory" subpopulation in PLWH. Since our populations of $\mathrm{mDC}$ might include monocytic/macrophage precursors, future studies on more purified mDCs remain to be done to determine whether these are monocytes/macrophages or a subpopulation of mDCs. In either case, we found that ART does not restore myeloid cell transcription to that of HIVuninfected persons.

\section{DISCUSSION}

This work, indicating changes in $\mathrm{mDC}$ associated with HIV infections, need to be considered in the development of ART. In this report, we compared gene expression in $\mathrm{mDC}$ from untreated and ART-treated PLWH, who were chronically HIV infected ( $\geq 1$ year post infection), compared to HIV-uninfected persons. Surprisingly, we found differences in gene expression in mDCs from ART-treated as well as untreated PLWH compared to that of uninfected healthy persons. This indicates that ART does not completely restore transcriptional changes that occur with HIV infections. The data presented herein reveal those 49 genes whose altered expression is common to ART and untreated HIV infections. Some of these genes are primarily considered to be indicative of a classical monocyte/macrophage lineage rather than a DC lineage. These genes include CD14, CD163, and the transcription factor, MAFB. We isolated $\mathrm{mDCs}$ by the canonical markers used to delineate DC at the time of the study. Our method employed an antibody-conjugated bead enrichment for $\mathrm{CD} \mathrm{c}^{+}$myeloid cells followed by FACS for mDCs based on size, $\mathrm{CD}_{11} \mathrm{c}^{+}, \mathrm{HLA}-\mathrm{DR}^{\text {intermediate-high }}$, and lineage negative $\left(\mathrm{CD}^{-}{ }^{-}\right.$, $\mathrm{CD}^{-} 9^{-}, \mathrm{CD}^{-} 6^{-}$) as well as $\mathrm{CD} 14^{-}$markers.

One explanation for our finding is related to a recent study of single-cell RNA sequencing (scRNAseq) of DC (10). This study showed that the $\mathrm{CD} 1 \mathrm{c}^{+} \mathrm{mDC}$ that we studied here is made up of two transcriptionally distinct $\mathrm{mDC}$ subpopulations in healthy individuals (10). The previously unidentified minor mDC subpopulation called "CD1c __B," or "inflammatory cDC2" expresses monocyte/macrophage genes including CD14 RNA in the absence of CD14 protein on the cell surface, which is what we found in our study. Villani et al. also found higher levels of CD163 and HMOX-1 in this mDC subpopulation than in classical CD $1 c^{+}$mDC [reviewed in Collin and Bigley (9)], similar to genes we observed whose transcription was increased in mDCs from PLWH. Thus, it is possible that the MDCs from PLWH have an increase in this "inflammatory" mDC subpopulation. Another report showed a CD1c ${ }^{+} \mathrm{mDC}$ subpopulation that expressed higher levels of MAFB, a transcription factor that had previously been ascribed to monocyte lineage that we also observed with increased transcription in ART-treated and TN PLWH (9, 59). This leads to the possibility that this newly identified 


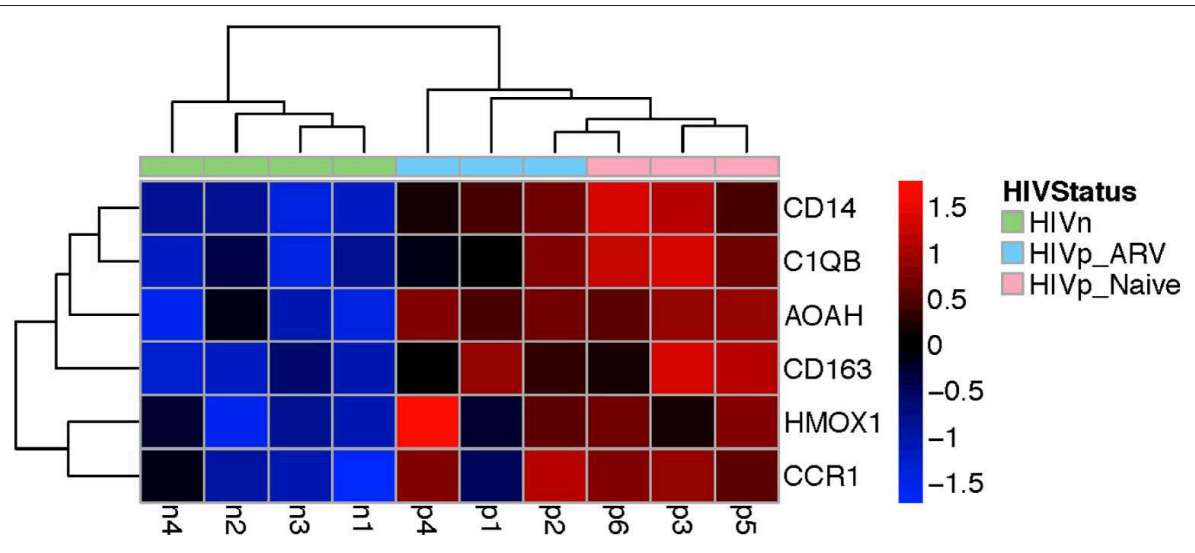

FIGURE 6 | Genes commonly upregulated in mDCs from TN and ARV-treated PLWH included those classically associated with the monocyte/macrophage lineage, myeloid cell differentiation, and inflammatory response. This heatmap shows a subset of those genes commonly upregulated in mDCs from TN or ARV-treated PLWH relative to HIV-uninfected persons. Supplementary Figure 3 illustrates, in more detail, the annotated functions of the genes shown.

mDC population that expresses genes previously associated with monocyte/macrophage, and whose role in health and disease has not yet been established, is an $\mathrm{mDC}$ subpopulation expanded in ART-treated and TN HIV infections.

Of those 49 genes altered in $\mathrm{mDC}$ from untreated and ARTtreated PLWH, we observed some of the highest increases in transcription of the acyloxyacyl hydrolase (AOAH) gene (fold change $=\sim 4)$. AOAH is a host lipase, which deacylates the gramnegative bacterial outer membrane component, LPS, rendering it less immunostimulatory to the host [reviewed in Munford et al. (60)]. AOAH is primarily expressed by antigen-presenting and phagocytic cells, including mDCs and monocytes $(60,61)$. AOAH mRNA is increased with LPS exposure of macrophage in vitro and in vivo (59). AOAH prevents prolonged responses to LPS when overexpressed in mouse DC $(62,63)$ and protects mice from inflammation-induced injury during gram-negative bacterial infections (59) as well as from gram-negative bacterial infection (63). Thus, the role of AOAH in HIV infections is somewhat paradoxical as PLWH are more susceptible to secondary infections, yet $\mathrm{AOAH}$ is associated with protection from gram-negative bacterial infections, at least in murine studies. Research has found a short nucleotide polymorphism (SNP) in an intron of the AOAH gene to be correlated with HIV RNA levels in PLWH (64). It may be that AOAH causes changes in $\mathrm{mDC}$ or myeloid cells that alters their ability to stimulate antiviral immunity, but this will need to be addressed in future studies targeted at understanding the role of AOAH in PLWH.

Some systems indicate that type I IFNs suppress IL-1 pathways, leading to increased susceptibility to bacterial and fungal infections (65-67). A type I IFN transcriptional profile in blood cells occurs in active MTB infection and is associated with MTB disease severity (68). The increased type I IFN transcriptional profile, alongside a suppressed IL-1 signaling pathway that we observed in mDC from TN PLWH, could be involved in enhancement of O.I.s such as MTB infections in PLWH. In this study, we found that ART restored type I IFN and IL-1 signaling pathways to near-HIV-uninfected levels. However, we found $\sim 70$ genes altered in myeloid cells enriched for mDC in ART-treated PLWH compared to HIVuninfected persons that were not in common with mDCs from untreated PLWH. Given the use of widespread use of pre-exposure prophylaxis (PrEP), these ART-specific changes should be further investigated for the effects of ART alone on myeloid cells.

The CD14 cell surface protein in HIV-uninfected persons has been used as a marker to differentiate blood monocytes and mDCs since monocytes have CD14 on their cell surface, whereas mDC generally do not. Here, we show a myeloid cell population that expresses CD14 RNA in the absence of significant levels of CD14 protein on the cell surface in PLWH. There are at least two ways to explain these results other than expansion of the newly described CD14 RNA-expressing mDC subpopulation in PLWH, as described above. CD14 is either shed from cells or internalized after binding to LPS $(69,70)$. This calls into question the utility of using the CD14 antibody as a marker to exclude, identify, or differentiate myeloid cell types in PLWH. Alternatively, a CD14 ${ }^{\text {low }}$ population of monocytes, known to be expanded in both ART-treated and untreated PLWH, albeit to a lesser extent after ART (71-73), may have been included in our mDC population in PLWH. Inclusion of an additional cell surface marker, CD16, will help exclude CD14 ${ }^{\text {low }}$ monocytes from the mDC population as CD14 ${ }^{\text {low }}$ monocytes co-express CD16 monocytes (74). For these reasons, we will refer to the myeloid cell population we have isolated as myeloid cells enriched for mDC. Importantly, we found common transcriptional changes in an enriched myeloid cell population in both ART and TN PLWH compared to HIV-uninfected individuals. Given more recent findings of two classes of $\mathrm{mDC}$, it should be possible in the future to determine whether this newly defined $\mathrm{mDC}$ subpopulation is expanded in untreated and ART-treated PLWH, or whether CD14 surface protein is internalized or shed from CD14 RNA-expressing cells that bind LPS in PLWH.

We found that ART does not restore gene transcription in mDCs from PLWH to HIV-uninfected levels. It may be that this represents changes in myeloid cell subpopulations that occur in TN and ART-treated PLWH. Even so, these transcriptional 
changes are not restored to HIV-uninfected levels with ART. It is known that high levels of CD14 and CD163 in the blood correlate with poor outcomes in including cardiovascular adverse events, fibrosis, and neurological abnormalities in ART-treated as well as TN PLWH [reviewed in Anzinger et al. (29)]. The $\mathrm{mDC}$ population that we have identified here may be responsible for the heightened levels of these proteins observed in PLWH, and thus targeting this myeloid cell population in ART would be important. Preliminary data from our lab indicate that plasma LPS levels correlate with CD14 RNA levels in the enriched mDC population in PLWH (unpublished data). This is consistent with the hypothesis that LPS is related to the $\mathrm{mDC}$ transcriptional changes that we observed in PLWH. Those 49 genes we have identified in mDCs that remain altered in PLWH with ART and have not previously been identified in biological studies in $\mathrm{PLWH}$, such as $\mathrm{AOAH}$, are candidates for further investigation in their role in HIV pathogenesis.

The participants in this study were pre-screened for nearnormal CD4 T-cell counts and overall good health to be eligible for apheresis for the isolation of mDC. Therefore, the TN PLWH in this study were skewed toward long-term non-progressors, who represent only $\sim 5-15 \%$ of the PLWH population (75), and therefore, this cohort does not reflect all TN PLWH. The majority of PLWH are progressors, who have a decline in CD4 T cells to $\leq 350$ cells/ $\mu$ l within the first 7 years post-HIV infection, at which time ART is initiated. It is not yet known whether the $\mathrm{mDC}$ transcriptional changes we observed are also seen in HIV progressors before ART treatment.

One of the ART-treated PLWH in this study was not completely virally suppressed, having plasma viral RNA loads of $\sim 400$ copies $/ \mathrm{ml}$. As we only collected measurements at one time point for the participants, we cannot ascertain whether this is a viral blip or ongoing viremia. In the future, it would be important to look at mDC samples from HIV progressors pre- and postART to determine whether the residual changes that we observed in ART-treated participants are reflected in longitudinal samples from HIV progressors.

One barrier to effective ART is the persistence of CD4 T cells that harbor latent HIV proviruses. It has been shown that $\mathrm{mDC}$ promote latency and HIV persistence in CD4 T cells $(76,77)$. Therefore, $\mathrm{mDC}$ should be investigated as targets of latencyreversing agents (LRAs), the current drugs used to eliminate latently HIV-infected cells in ART PLWH, since the effects of these drugs on $\mathrm{mDC}$ have not been delineated. Of note, the cohort we studied included PLWH who had been taking ART for over 12 years and individuals HIV infected for up to 20 years. Thus, changes in mDCs were not restored to baseline by ART despite long times post HIV infection and ART initiation. In the future, new ART protocols should be developed to target these myeloid and mDC alterations. The findings described here, of

\section{REFERENCES}

1. Steinman RM. The dendritic cell system and its role in immunogenicity. Annu Rev Immunol. (1991) 9:271-96. doi: 10.1146/annurev.iy.09.040191.001415

2. Merad M, Manz MG. Dendritic cell homeostasis. Blood. (2009) 113:3418-27. doi: 10.1182/blood-2008-12-180646 transcriptional changes in myeloid cells enriched for $\mathrm{mDC}$ from $\mathrm{PLWH}$, including AOAH, should be further investigated for their relationship to O.I.s, correlates of HIV disease progression, and role in HIV persistence.

\section{DATA AVAILABILITY STATEMENT}

The datasets generated for this study can be found in the National Center for Biotechnology Information Gene Expression Omnibus (GEO) under accession no. GSE139559, https://www. ncbi.nlm.nih.gov/geo/query/acc.cgi?acc=GSE139559.

\section{ETHICS STATEMENT}

The studies involving human participants were reviewed and approved by the National Institute of Allergy and Infectious Diseases or the Vaccine and Gene Therapy Institute Florida. The patients/participants provided their written informed consent to participate in this study.

\section{AUTHOR CONTRIBUTIONS}

SM was responsible for conceptualizing, writing the manuscript, and performing the experiments. YZ performed the experiments and contributed to the methods. DD and RS were responsible for conceptualizing the experiments as well as advising and funding of the project.

\section{FUNDING}

This work was supported in part by the intramural program of the NIAID, NIH, and NIH R37 (Number: R37AI141258 to RS). Publication and open access fees were paid by the Fred Hutchinson Cancer Research Center, Case Western Reserve University, and the NIAID, NIH.

\section{ACKNOWLEDGMENTS}

We thank Maxine Linial for her critical reading and evaluation of the manuscript. We thank Julia James Zuze for the helpful discussion. We thank Francois Lefebvre, Ali Filali-Mouhim, and Mark Cameron for the assistance with bioinformatics analyses. We thank the Vaccine Research Center Clinic Staff and the study participants.

\section{SUPPLEMENTARY MATERIAL}

The Supplementary Material for this article can be found online at: https://www.frontiersin.org/articles/10.3389/fimmu. 2020.00261/full\#supplementary-material

3. Fogg DK, Sibon C, Miled C, Jung S, Aucouturier P, Littman DR, et al. A clonogenic bone marrow progenitor specific for macrophages and dendritic cells. Science. (2006) 311:83-7. doi: 10.1126/science.1117729

4. Geissmann F, Manz MG, Jung S, Sieweke MH, Merad M, Ley K. Development of monocytes, macrophages, and dendritic cells. Science. (2010) 327:656-61. doi: $10.1126 /$ science. 1178331 
5. Satpathy AT, Wu X, Albring JC, Murphy KM. Re(de)fining the dendritic cell lineage. Nat Immunol. (2012) 13:1145-54. doi: 10.1038/ni.2467

6. Shortman K, Liu YJ. Mouse and human dendritic cell subtypes. Nat Rev Immunol. (2002) 2:151-61. doi: 10.1038/nri746

7. Shortman K, Naik SH. Steady-state and inflammatory dendritic-cell development. Nat Rev Immunol. (2007) 7:19-30. doi: 10.1038/nri1996

8. Heidkamp GF, Sander J, Lehmann CHK, Heger L, Eissing N, Baranska A, et al. Human lymphoid organ dendritic cell identity is predominantly dictated by ontogeny, not tissue microenvironment. Sci Immunol. (2016) 1:eaai7677. doi: 10.1126/sciimmunol.aai7677

9. Collin M, Bigley V. Human dendritic cell subsets: an update. Immunology. (2018) 154:3-20. doi: 10.1111/imm.12888

10. Villani AC, Satija R, Reynolds G, Sarkizova S, Shekhar K, Fletcher J, et al. Single-cell RNA-seq reveals new types of human blood dendritic cells, monocytes, and progenitors. Science. (2017) 356. doi: 10.1126/science.aah4573

11. Cattin A, Wiche Salinas TR, Gosselin A, Planas D, Shacklett B, Cohen EA, et al. HIV-1 is rarely detected in blood and colon myeloid cells during viral-suppressive antiretroviral therapy. AIDS. (2019) 33:1293-306. doi: 10.1097/QAD.0000000000002195

12. Miller EA, Spadaccia MR, O’Brien MP, Rolnitzky L, Sabado R, Manches O, et al. Plasma factors during chronic HIV-1 infection impair IL-12 secretion by myeloid dendritic cells via a virus-independent pathway. J Acquir Immune Defic Syndr. (2012) 61:535-44. doi: 10.1097/QAI.0b013e31826afbce

13. Grassi F, Hosmalin A, Mcllroy D, Calvez V, Debre P, Autran B. Depletion in blood CD11c-positive dendritic cells from HIV-infected patients. AIDS. (1999) 13:759-66. doi: 10.1097/00002030-199905070-00004

14. Donaghy H, Pozniak A, Gazzard B, Qazi N, Gilmour J, Gotch F, et al. Loss of blood $\mathrm{CD} 11 \mathrm{c}(+)$ myeloid and $\mathrm{CD} 11 \mathrm{c}(-)$ plasmacytoid dendritic cells in patients with HIV-1 infection correlates with HIV-1 RNA virus load. Blood. (2001) 98:2574-6. doi: 10.1182/blood.V98.8.2574

15. Barron MA, Blyveis N, Palmer BE, MaWhinney S, Wilson CC. Influence of plasma viremia on defects in number and immunophenotype of blood dendritic cell subsets in human immunodeficiency virus 1-infected individuals. J Infect Dis. (2003) 187:26-37. doi: 10.1086/345957

16. Fontaine J, Coutlee F, Tremblay C, Routy JP, Poudrier J, Roger M, et al. HIV infection affects blood myeloid dendritic cells after successful therapy and despite nonprogressing clinical disease. J Infect Dis. (2009) 199:1007-18. doi: $10.1086 / 597278$

17. Dutertre CA, Amraoui S, DeRosa A, Jourdain JP, Vimeux L, Goguet M, et al. Pivotal role of $\mathrm{M}-\mathrm{DC}^{+}{ }^{+}$monocytes from viremic HIV-infected patients in TNF $\alpha$ overproduction in response to microbial products. Blood. (2012) 120:2259-68. doi: 10.1182/blood-2012-03-418681

18. Brown KN, Trichel A, Barratt-Boyes SM. Parallel loss of myeloid and plasmacytoid dendritic cells from blood and lymphoid tissue in simian AIDS. J Immunol. (2007) 178:6958-67. doi: 10.4049/jimmunol.178.11.6958

19. Wijewardana V, Soloff AC, Liu X, Brown KN, Barratt-Boyes SM. Early myeloid dendritic cell dysregulation is predictive of disease progression in simian immunodeficiency virus infection. PLoS Pathog. (2010) 6:e1001235. doi: 10.1371/journal.ppat. 1001235

20. Geijtenbeek TB, Kwon DS, Torensma R, van Vliet SJ, van Duijnhoven GC, Middel J, et al. DC-SIGN, a dendritic cell-specific HIV-1-binding protein that enhances trans-infection of T cells. Cell. (2000) 100:587-97. doi: 10.1016/S0092-8674(00)80694-7

21. Izquierdo-Useros N, Lorizate M, Puertas MC, Rodriguez-Plata MT, Zangger $\mathrm{N}$, Erikson E, et al. Siglec-1 is a novel dendritic cell receptor that mediates HIV-1 trans-infection through recognition of viral membrane gangliosides. PLoS Biol. (2012) 10:e1001448. doi: 10.1371/journal.pbio.1001448

22. Manches O, Frleta D, Bhardwaj N. Dendritic cells in progression and pathology of HIV infection. Trends Immunol. (2014) 35:114-22. doi: 10.1016/j.it.2013.10.003

23. Nockher WA, Bergmann L, Scherberich JE. Increased soluble CD14 serum levels and altered CD14 expression of peripheral blood monocytes in HIV-infected patients. Clin Exp Immunol. (1994) 98:369-74. doi: 10.1111/j.1365-2249.1994.tb05499.x

24. Lien E, Aukrust P, Sundan A, Muller F, Froland SS, Espevik T. Elevated levels of serum-soluble CD14 in human immunodeficiency virus type 1 (HIV-1) infection: correlation to disease progression and clinical events. Blood. (1998) 92:2084-92. doi: 10.1182/blood.V92.6.2084

25. Burdo TH, Soulas C, Orzechowski K, Button J, Krishnan A, Sugimoto C, et al. Increased monocyte turnover from bone marrow correlates with severity of SIV encephalitis and CD163 levels in plasma. PLoS Pathog. (2010) 6:e1000842. doi: 10.1371/journal.ppat.1000842

26. Burdo TH, Lentz MR, Autissier P, Krishnan A, Halpern E, Letendre S, et al Soluble CD163 made by monocyte/macrophages is a novel marker of HIV activity in early and chronic infection prior to and after anti-retroviral therapy. J Infect Dis. (2011) 204:154-63. doi: 10.1093/infdis/jir214

27. Burdo TH, Lo J, Abbara S, Wei J, DeLelys ME, Preffer F, et al. Soluble CD163, a novel marker of activated macrophages, is elevated and associated with noncalcified coronary plaque in HIV-infected patients. J Infect Dis. (2011) 204:1227-36. doi: 10.1093/infdis/jir520

28. Sandler NG, Wand H, Roque A, Law M, Nason MC, Nixon DE, et al. Plasma levels of soluble CD14 independently predict mortality in HIV infection. $J$ Infect Dis. (2011) 203:780-90. doi: 10.1093/infdis/jiq118

29. Anzinger JJ, Butterfield TR, Angelovich TA, Crowe SM, Palmer CS, Monocytes as regulators of inflammation and HIV-related comorbidities during cART. J Immunol Res. (2014) 2014:569819. doi: 10.1155/2014/569819

30. Longenecker CT, Jiang Y, Orringer CE, Gilkeson RC, Debanne S, Funderburg NT, et al. Soluble CD14 is independently associated with coronary calcification and extent of subclinical vascular disease in treated HIV infection. AIDS. (2014) 28:969-77. doi: 10.1097/QAD.0000000000000158

31. Srinivasa S, Fitch KV, Petrow E, Burdo TH, Williams KC, Lo J, et al. Soluble CD163 is associated with shortened telomere length in HIV-infected patients. J Acquir Immune Defic Syndr. (2014) 67:414-8. doi: 10.1097/QAI.0000000000000329

32. Walker JA, Sulciner ML, Nowicki KD, Miller AD, Burdo TH, Williams KC. Elevated numbers of $\mathrm{CD}_{163}{ }^{+}$macrophages in hearts of simian immunodeficiency virus-infected monkeys correlate with cardiac pathology and fibrosis. AIDS Res Hum Retroviruses. (2014) 30:685-94. doi: 10.1089/aid.2013.0268

33. Brenchley JM, Price DA, Schacker TW, Asher TE, Silvestri G, Rao S, et al. Microbial translocation is a cause of systemic immune activation in chronic HIV infection. Nat Med. (2006) 12:1365-71. doi: 10.1038/nm1511

34. Jiang W, Lederman MM, Hunt P, Sieg SF, Haley K, Rodriguez B, et al. Plasma levels of bacterial DNA correlate with immune activation and the magnitude of immune restoration in persons with antiretroviral-treated HIV infection. $J$ Infect Dis. (2009) 199:1177-85. doi: 10.1086/597476

35. Merlini E, Bai F, Bellistri GM, Tincati C, d'Arminio Monforte A, Marchetti G. Evidence for polymicrobic flora translocating in peripheral blood of HIVinfected patients with poor immune response to antiretroviral therapy. PLoS ONE. (2011) 6:e18580. doi: 10.1371/journal.pone.0018580

36. Brenchley JM, Schacker TW, Ruff LE, Price DA, Taylor JH, Beilman GJ, et al. $\mathrm{CD}^{+} \mathrm{T}$ cell depletion during all stages of HIV disease occurs predominantly in the gastrointestinal tract. J Exp Med. (2004) 200:749-59. doi: $10.1084 /$ jem.20040874

37. Brenchley JM, Douek DC. The mucosal barrier and immune activation in HIV pathogenesis. Curr Opin HIV AIDS. (2008) 3:356-61. doi: 10.1097/COH.0b013e3282f9ae9c

38. Brenchley JM, Douek DC. HIV infection and the gastrointestinal immune system. Mucosal Immunol. (2008) 1:23-30. doi: 10.1038/mi.2007.1

39. Giorgi JV, Liu Z, Hultin LE, Cumberland WG, Hennessey K, Detels R. Elevated levels of $\mathrm{CD}_{3} 8^{+} \mathrm{CD}^{+} \mathrm{T}$ cells in HIV infection add to the prognostic value of low $\mathrm{CD}^{+} \mathrm{T}$ cell levels: results of 6 years of follow-up. The Los Angeles Center, Multicenter AIDS Cohort Study. J Acquir Immune Defic Syndr. (1993) 6:904-12.

40. Liu Z, Hultin LE, Cumberland WG, Hultin P, Schmid I, Matud $\mathrm{JL}$, et al. Elevated relative fluorescence intensity of CD38 antigen expression on $\mathrm{CD}^{+} \mathrm{T}$ cells is a marker of poor prognosis in HIV infection: results of 6 years of follow-up. Cytometry. (1996) 26:1-7. doi: 10.1002/(SICI)1097-0320(19960315)26:1 <1::AID-CYTO1 > 3.0.CO;2-L

41. Liu Z, Cumberland WG, Hultin LE, Prince HE, Detels R, Giorgi JV. Elevated $\mathrm{CD} 38$ antigen expression on $\mathrm{CD} 8^{+} \mathrm{T}$ cells is a stronger marker for the risk of chronic HIV disease progression to AIDS and death in the Multicenter AIDS Cohort Study than $\mathrm{CD}^{+}$cell count, soluble immune activation markers, or 
combinations of HLA-DR and CD38 expression. J Acquir Immune Defic Syndr Hum Retrovirol. (1997) 16:83-92. doi: 10.1097/00042560-199710010-00003

42. Hultin LE, Matud JL, Giorgi JV. Quantitation of CD38 activation antigen expression on CD8 $+\mathrm{T}$ cells in HIV-1 infection using CD4 expression on $\mathrm{CD}^{+}$T lymphocytes as a biological calibrator. Cytometry. (1998) 33:123-32. doi: 10.1002/(sici)1097-0320(19981001)33:2<123::aid-cyto6>3.0.co;2-k

43. Lawn SD, Harries AD, Williams BG, Chaisson RE, Losina E, De Cock $\mathrm{KM}$, et al. Antiretroviral therapy and the control of HIV-associated tuberculosis. Will ART do it? Int J Tuberc Lung Dis. (2011) 15:571-81. doi: $10.5588 /$ ijtld. 10.0483

44. Pawlowski A, Jansson M, Skold M, Rottenberg ME, Kallenius G. Tuberculosis and HIV co-infection. PLoS Pathog. (2012) 8:e1002464. doi: 10.1371/journal.ppat.1002464

45. Durai V, Murphy KM. Functions of murine dendritic cells. Immunity. (2016) 45:719-36. doi: 10.1016/j.immuni.2016.10.010

46. Berger TG, Strasser E, Smith R, Carste C, Schuler-Thurner B, Kaempgen E, et al. Efficient elutriation of monocytes within a closed system (Elutra) for clinical-scale generation of dendritic cells. J Immunol Methods. (2005) 298:61-72. doi: 10.1016/j.jim.2005.01.005

47. Kim S, Kim HO, Baek EJ, Choi Y, Kim HS, Lee MG. Monocyte enrichment from leukapheresis products by using the Elutra cell separator. Transfusion. (2007) 47:2290-6. doi: 10.1111/j.1537-2995.2007.01470.x

48. Schroder M, Melum GR, Landsverk OJ, Bujko A, Yaqub S, Gran E, et al. CD1c-Expression by monocytes - implications for the use of commercial $\mathrm{CD}_{1}{ }^{+}$dendritic cell isolation kits. PLoS ONE. (2016) 11:e0157387. doi: 10.1371 /journal.pone. 0157387

49. Caskey M, Lefebvre F, Filali-Mouhim A, Cameron MJ, Goulet JP, Haddad EK, et al. Synthetic double-stranded RNA induces innate immune responses similar to a live viral vaccine in humans. J Exp Med. (2011) 208:2357-66. doi: $10.1084 /$ jem.20111171

50. Gentleman RC, Carey VJ, Bates DM, Bolstad B, Dettling M, Dudoit S, et al. Bioconductor: open software development for computational biology and bioinformatics. Genome Biol. (2004) 5:R80. doi: 10.1186/gb-2004-5-10-r80

51. Johnson WE, Li C, Rabinovic A. Adjusting batch effects in microarray expression data using empirical Bayes methods. Biostatistics. (2007) 8:118-27. doi: 10.1093/biostatistics/kxj037

52. Smyth GK. Linear models and empirical bayes methods for assessing differential expression in microarray experiments. Stat Appl Genet Mol Biol. (2004) 3:Article3. doi: 10.2202/1544-6115.1027

53. Benjamini $Y$, Hochberg Y. Controlling the false discovery rate: a practical and powerful approach to multiple testing. J R Stat Soc Series B Stat Methodol. (1995) 57:289-300. doi: 10.1111/j.2517-6161.1995.tb02031.x

54. Grennan JT, Loutfy MR, Su D, Harrigan PR, Cooper C, Klein M, et al. Magnitude of virologic blips is associated with a higher risk for virologic rebound in HIV-infected individuals: a recurrent events analysis. J Infect Dis. (2012) 205:1230-8. doi: 10.1093/infdis/jis104

55. Gurdasani D, Iles L, Dillon DG, Young EH, Olson AD, Naranbhai V, et al. A systematic review of definitions of extreme phenotypes of HIV control and progression. AIDS. (2014) 28:149-62. doi: 10.1097/QAD.0000000000000049

56. Mayer-Barber KD, Yan B. Clash of the Cytokine Titans: counter-regulation of interleukin-1 and type I interferon-mediated inflammatory responses. Cell Mol Immunol. (2017) 14:22-35. doi: 10.1038/cmi.2016.25

57. Caamano J, Hunter CA. NF-kappaB family of transcription factors: central regulators of innate and adaptive immune functions. Clin Microbiol Rev. (2002) 15:414-29. doi: 10.1128/CMR.15.3.414-429.2002

58. Dorrington MG, Fraser IDC. NF- $\mathrm{kB}$ signaling in macrophages: dynamics, crosstalk, and signal integration. Front Immunol. (2019) 10:705. doi: 10.3389/fimmu.2019.00705

59. Zou B, Jiang W, Han H, Li J, Mao W, Tang Z, et al. Acyloxyacyl hydrolase promotes the resolution of lipopolysaccharide-induced acute lung injury. PLoS Pathog. (2017) 13:e1006436. doi: 10.1371/journal.ppat.1006436

60. Munford R, Lu M, Varley A. Chapter 2: kill the bacteria...and also their messengers? Adv Immunol. (2009) 103:29-48. doi: 10.1016/S0065-2776(09)03002-8

61. Lu M, Zhang M, Kitchens RL, Fosmire S, Takashima A, Munford RS. Stimulus-dependent deacylation of bacterial lipopolysaccharide by dendritic cells. J Exp Med. (2003) 197:1745-54. doi: 10.1084/jem.20030420
62. Lu M, Varley AW, Ohta S, Hardwick J, Munford RS. Host inactivation of bacterial lipopolysaccharide prevents prolonged tolerance following gram-negative bacterial infection. Cell Host Microbe. (2008) 4:293-302. doi: 10.1016/j.chom.2008.06.009

63. Ojogun N, Kuang TY, Shao B, Greaves DR, Munford RS, Varley AW. Overproduction of acyloxyacyl hydrolase by macrophages and dendritic cells prevents prolonged reactions to bacterial lipopolysaccharide in vivo.J Infect Dis. (2009) 200:1685-93. doi: 10.1086/646616

64. Pelak K, Goldstein DB, Walley NM, Fellay J, Ge D, Shianna KV, et al. Host determinants of HIV-1 control in African Americans. J Infect Dis. (2010) 201:1141-9. doi: 10.1086/651382

65. Hu X, Ho HH, Lou O, Hidaka C, Ivashkiv LB. Homeostatic role of interferons conferred by inhibition of IL-1-mediated inflammation and tissue destruction. J Immunol. (2005) 175:131-8. doi: 10.4049/jimmunol.175.1.131

66. Guarda G, Braun M, Staehli F, Tardivel A, Mattmann C, Forster I, et al. Type I interferon inhibits interleukin-1 production and inflammasome activation. Immunity. (2011) 34:213-23. doi: 10.1016/j.immuni.2011.02.006

67. Mayer-Barber KD, Andrade BB, Oland SD, Amaral EP, Barber DL, Gonzales J, et al. Host-directed therapy of tuberculosis based on interleukin-1 and type I interferon crosstalk. Nature. (2014) 511:99-103. doi: 10.1038/nature13489

68. Berry MP, Graham CM, McNab FW, Xu Z, Bloch SA, Oni T, et al. An interferon-inducible neutrophil-driven blood transcriptional signature in human tuberculosis. Nature. (2010) 466:973-7. doi: 10.1038/nature09247

69. Bazil V, Strominger JL. Shedding as a mechanism of down-modulation of CD14 on stimulated human monocytes. J Immunol. (1991) 147:1567-74.

70. Labeta MO, Durieux JJ, Fernandez N, Herrmann R, Ferrara P. Release from a human monocyte-like cell line of two different soluble forms of the lipopolysaccharide receptor, CD14. Eur J Immunol. (1993) 23:2144-51. doi: 10.1002/eji.1830230915

71. Thieblemont N, Weiss L, Sadeghi HM, Estcourt C, Haeffner-Cavaillon N. CD14lowCD16high: a cytokine-producing monocyte subset which expands during human immunodeficiency virus infection. Eur J Immunol. (1995) 25:3418-24. doi: 10.1002/eji.1830251232

72. Ellery PJ, Crowe SM. Phenotypic characterization of blood monocytes from HIV-infected individuals. Methods Mol Biol. (2005) 304:343-53. doi: 10.1385/1-59259-907-9:343

73. Funderburg NT, Zidar DA, Shive C, Lioi A, Mudd J, Musselwhite LW, et al. Shared monocyte subset phenotypes in HIV-1 infection and in uninfected subjects with acute coronary syndrome. Blood. (2012) 120:4599608. doi: 10.1182/blood-2012-05-433946

74. Ziegler-Heitbrock L, Ancuta P, Crowe S, Dalod M, Grau V, Hart DN, et al. Nomenclature of monocytes and dendritic cells in blood. Blood. (2010) 116:e74-80. doi: 10.1182/blood-2010-02-258558

75. Okulicz JF, Marconi VC, Landrum ML, Wegner S, Weintrob A, Ganesan A, et al. Clinical outcomes of elite controllers, viremic controllers, and long-term nonprogressors in the US Department of Defense HIV natural history study. J Infect Dis. (2009) 200:1714-23. doi: 10.1086/646609

76. Evans VA, Kumar N, Filali A, Procopio FA, Yegorov O, Goulet JP, et al. Myeloid dendritic cells induce HIV-1 latency in non-proliferating CD4 ${ }^{+}$T cells. PLoS Pathog. (2013) 9:e1003799. doi: 10.1371/journal.ppat. 1003799

77. Kumar NA, van der Sluis RM, Mota T, Pascoe R, Evans VA, Lewin SR, et al. Myeloid dendritic cells induce HIV latency in proliferating $\mathrm{CD}^{+}$T cells. J Immunol. (2018) 201:1468-77. doi: 10.4049/jimmunol. 1701233

Conflict of Interest: The authors declare that the research was conducted in the absence of any commercial or financial relationships that could be construed as a potential conflict of interest.

Copyright $\odot 2020$ Murray, Zhang, Douek and Sekaly. This is an open-access article distributed under the terms of the Creative Commons Attribution License (CC BY). The use, distribution or reproduction in other forums is permitted, provided the original author(s) and the copyright owner(s) are credited and that the original publication in this journal is cited, in accordance with accepted academic practice. No use, distribution or reproduction is permitted which does not comply with these terms. 